\title{
SOROTAN LITERATUR TERHADAP TUNTUTAN SELEPAS PERCERAIAN BAGI WANITA MUSLIM DI TIGA WILAYAH SELATAN THAILAND
}

\section{Literature Review on Claims After Divorce for Muslim Women in the Three Southern Provinces of Thailand}

\author{
Mahamatayuding Samah \\ Senior Lecturer, Department of Shariah and Law, \\ Academy of Islamic Studies, \\ University of Malaya, 50603 Kuala Lumpur. \\ mahyudin@um.edu.my \\ Raihanah Abdullah \\ Professor, Department of Shariah and Law, \\ Academy of Islamic Studies, \\ University of Malaya, 50603 Kuala Lumpur. \\ raihanah@um.edu.my
}

\begin{abstract}
Claims after the divorce of Muslim women in the three southern Thailand provinces have been allocated through the application of Islamic Law 1946. However, it should be analyzed to see how far the women's rights are protected and implemented in Muslim communities in three southern Thailand provinces. In this study, the author has analyzed and studied the files in the civil courts pertaining to the issue of mut'ah, maintenance of 'iddah, dowries, custody and matrimonial property. This study revealed that the number of claims after divorce in civil courts are at low levels despite the court played a positive role towards strengthening the application of Islamic law.
\end{abstract}

Keywords: marital claims, Islamic Family Law, southern Thailand 


\section{PENDAHULUAN}

Persoalan mengenai wanita, statusnya dalam masyarakat dan hak-hak mereka bukanlah sesuatu yang asing memandangkan al-Quran sendiri telah memperuntukan secara spesifik tentang wanita serta kedudukannya sekarang berbanding dengan kedudukan mereka pada zaman Jahiliyah. Wanita telah diberikan dengan pelbagai hak yang bukan sahaja melibatkan urusan kekeluargaan, bahkan juga hal-hal berkaitan dengan kemasyarakatan. Keadaan tersebut bertambah jelas setelah didapati penulisan-penulisan barat memperakui bahawa Syariah Islam telah memartabatkan kedudukan wanita terutama dalam soal kekeluargaan (J.N.D. Anderson, 1959: 4; Noel Coulson \& Doreen Hinchcliffe, 1978: 37-38).

Walaupun wanita Islam telah diberi dengan pelbagai hak, ternyata kadangkala kehidupan mereka tidak sebagaimana yang dinyatakan dalam al-Quran. Banyak kisah dalam masyarakat menggambarkan bahawa wanita itu teraniaya dan kehidupannya sangatlah malang. Peristiwa seperti ini sememangnya berlaku dalam sesebuah masyarakat Islam.

Isu-isu seperti perceraian dan tuntutan wanita setelah dicerai termasuk isu mut'ah, nafkah 'iddah, mahar (maskahwin) tertunggak dan harta sepencarian bukanlah suatu fenomena asing dalam kalangan wanita Islam di tiga wilayah selatan Thailand. Tiada peruntukan undang-undang yang cukup dan lengkap bagi mengatasi masalah yang dihadapi oleh mereka. Apa yang penting ialah kefahaman masyarakat terhadap tugas, peranan dan tanggungjawab yang mesti dimainkan oleh setiap individu agar tidak berlaku sebarang penyelewengan dan penganiayaan dalam masyarakat (Abd. Rahman Che'arong, 2003: 5-15).

\section{SOROTAN LITERATUR}

Terdapat banyak kajian atau penulisan yang dijalankan berkaitan dengan tuntutan selepas perceraian bagi wanita Islam. Kajian tersebut dijalankan dalam pelbagai perspektif sama ada dalam perspektif fiqh dan perspektif undang-undang. Dalam perspektif fiqh dan undang-undang, buku yang agak menonjol di sekitar tahun 1957 ialah buku tulisan al-Imam Muhammad Abu Zahrah (1957: 169-175) yang bertajuk al-Ahwāl al-Syakhsiyyah yang telah membincangkan soal hak-hak wanita dari aspek tuntutan terhadap suami dengan begitu jelas. Terutama sekali perbincangan berkaitan dengan mahar atau maskahwin bagi wanita, isu-isu mahar, perbincangan berkaitan mut'ah dan nafkah seterusnya perkara-perkara yang berkaitan dengan penentuan nafkah. Muhammad Abu Zahrah menulis dengan mempelbagaikan pandangan 
ulama serta menonjolkan pandangannya dalam apa jua isu berasaskan roh dan kehendak syariat.

Tulisan berkaitan dengan perkahwinan dan kewajipan suami isteri dihasilkan oleh Zakī al-Dīn Sya'bān (1964: 11) dalam buku yang bertajuk al-Zawāj wa al-Talāq fì al-Islām membincangkan tentang hak-hak hasil dari perkahwinan suami isteri. Tegasnya hubungan suami isteri akan menjadi stabil apabila kedua-dua suami isteri saling memelihara tanggungjawab masingmasing serta melakukan sesuatu yang terbaik untuk mereka berdua. Tugas dan tanggungjawab ini ada beberapa perkara, sesetengahnya berkaitan dengan suami dan sesetengah yang lain pula, berkaitan dengan isteri.

Tulisan tentang nafkah isteri dihasilkan oleh Muhammad Zakariyya al-Bardisī (1970: 7-10) yang membincangkan secara mendalam tentang nafkah sama ada isteri tergolong dalam golongan tua atau isteri masih muda tetapi menghadapi kesakitan atau enggan berpindah untuk bersama suami. Bagaimanapun, apa yang menarik dalam tulisan buku ini ialah setiap isu yang diperbincangkan disertai dengan undang-undang keluarga Islam yang terpakai di Mesir.

Selanjutnya, tulisan yang merangkumi semua aspek tuntutan wanita Islam selepas perceraian sama ada berkaitan dengan mut'ah, nafkah, mahar dan hak hadānah diperjelaskan dalam dua buah buku yang berasingan. Pertama, buku yang dihasilkan oleh Muhammad 'Uqlah (1983: 20-30) yang bertajuk Niz̄ām al-Usrah fì al-Islām. Kedua, buku yang dihasilkan oleh Mustafa 'Abd al-Ghanī Syībah (2006: 10-20) yang bertajuk Ahkām al-Usrah fì al-Syarī'ah al-Islāmiyyah.

Dalam satu sorotan literatur yang dilakukan oleh Raihanah Abdullah (2005: 127-132) menyatakan bahawa di sekitar tahun 1960-an, terdapat kajian dalam aspek kekeluargaan dan pelaksanaan undang-undang kekeluargaan Islam seperti yang diperuntukkan di dalam Undang-Undang Pentadbiran Agama Islam. Ahmad Ibrahim (1965: 147) dalam bukunya yang bertajuk The Status of Muslim Women in Malaysia, Singapore and Brunei telah membincangkan soal kedudukan wanita dalam undang-undang keluarga menurut enakmen pentadbiran agama Islam yang berkuatkuasa pada ketika itu bukan sahaja di Malaysia, bahkan termasuk juga Singapura dan Brunei. Antara kesimpulan penting dalam penulisan tersebut ialah peruntukan kekeluargaan Islam seperti yang diperuntukkan dalam enakmen pentadbiran undang-undang Islam pada masa itu amatlah sedikit dan tidak mengambil kira faktor semasa.

Analisis mengenai pelaksanaan dan pentadbiran undang-undang keluarga Islam juga dibuat oleh Ahmad Ibrahim (1965: 26-28) di dalam bukunya yang bertajuk Islamic Law in Malaya. Perbincangan buku ini lebih memfokuskan 
negeri-negeri di Malaysia dengan skop yang lebih luas dengan memasukkan bidang jenayah, keterangan, harta dan acara. Walau bagaimanapun, perbincangan mengenai undang-undang keluarga tidak banyak berbeza dengan perbincangan yang dibuat dalam buku The Status of Muslim Women in Malaysia, Singapore and Brunei.

Kupasan selanjutnya juga dihasikan oleh Ahmad Ibrahim (1999: 9, 187) dalam bukunya iaitu Undang-Undang Keluarga Islam di Malaysia yang menyentuh dan menyingkap sejarah penerimaan undang-undang Islam di Tanah Melayu dengan wujudnya risalah Hukum Kanun Melaka yang kemudiannya mempengaruhi undang-undang di negeri-negeri lain. Undangundang yang diguna pakai sebelum kedatangan British adalah undang-undang Islam yang bercampur aduk dengan undang-undang adat. Seterusnya, beliau juga menyentuh tentang perintah-perintah sampingan akibat dari pembubaran perkahwinan, termasuk mut'ah yang menjadi kewajipan pihak suami memberikannya kepada pihak isteri sama ada si isteri melakukan nusyuz atau tidak. Begitu juga persoalan mengenai nafkah semasa iddah yang menjadi tanggungjawab suami dan jumlah yang tidak dipersetujui dibuat di mahkamah, maskahwin yang belum dibayar kerana ia adalah hak isteri. Satu lagi hak yang unik iaitu tuntutan harta sepencarian boleh dibuat sama ada pihak isteri atau suami. Hak harta sepencarian yang diterima pakai di Malaysia adalah berasal dari hukum adat tetapi diterima pakai sebagai sebahagian Hukum Islam.

Penulisan dalam bentuk undang-undang keluarga Islam menjadi lebih ke hadapan pada tahun 1990-an dengan penumpuan para penulis kepada aspek pelaksanaannya. Topik-topik yang disentuh dalam penulisan-penulisan peringkat ini ialah perceraian (Ahmad Ibrahim, 1978: 229-346), nafkah (Abdul Kadir Muhammad, 1996: 85), mut'ah (Nik Noriani Nik Badlishah, 1992: 123) dan (Raihanah Azahari, 2001: 141-159), harta sepencarian (Suwaid Tapah, 2003: 56-65) dan had̄̄nah (Sharifah Zaharah Syed Mohammad, 2001: 160200). Pada umumnya, perbincangan mereka lebih mencari jawapan sama ada peruntukan-peruntukan kekeluargaan yang terdapat di dalam enakmen undangundang keluarga Islam adalah mencukupi untuk menangani beberapa masalah atau mengupas peruntukan tersebut dari sudut pelaksanaannya. Mereka juga telah memberi cadangan-cadangan yang berguna bagi mengatasi kekurangan yang terdapat di bahagian pentadbiran kes dan mahkamah.

Analisis dalam bentuk perbandingan (comparative legal perspective) dengan negara-negara jiran telah dilakukan oleh Zaleha Kamaruddin (2000: 1-16) dalam koleksi artikel yang disuntingnya berjudul Islamic Family Law Issues. Penulisan sebegini bukan sahaja membincangkan aspek-aspek khusus dalam undang-undang keluarga Islam dan bagaimana ianya dilaksanakan 
di negara-negara yang lain, tetapi juga turut membincangkan persoalan dan konsep pembaharuan undang-undang keluarga Islam. Melalui pendekatan perbandingan ini, terdapat beberapa cadangan daripada penulisan-penulisan tersebut agar peruntukan-peruntukan daripada undang-undang keluarga negara-negara Islam yang lain perlu diberi perhatian untuk dikuatkuasakan di Malaysia.

Selain itu, terdapat juga kajian yang dilakukan dalam masyarakat Islam di tiga wilayah selatan Thailand. Di antaranya ialah sebagaimana yang dilakukan oleh Surin Pitsuan ${ }^{1}$ (1989: 100-125) di dalam bukunya Islam di Muang Thai: Nasionalisme Masyarakat Melayu Pattani. Buku yang berasal dari sebuah Tesis Doktor Falsafah University Harvard (1982: 20-30). Sebahagian besar isi perbincangan dalam buku ini memberi gambaran yang jelas tentang gerakan Islam di Patani yang dipimpin oleh golongan ulama sepertimana yang juga berlaku di negara-negara lain. Gambaran-gambaran di dalam buku ini sudah pasti akan menjadi bahan rujukan penulis dalam membuat formula dalam menangani isu-isu yang berkaitan khususnya untuk meneruskan kelangsungan pelaksanaan undang-undang Islam.

Tumpuan dalam aspek pentadbiran undang-undang Islam di Asia Tenggara yang termasuk didalamnya mengenai pentadbiran undang-undang Islam di Thailand telah ditulis oleh M.B. Hooker (1984: 37) dalam bukunya Islamic Law in South East Asia. Dalam buku ini, beliau menegaskan bahawa penduduk Islam yang berbangsa Melayu di Selatan Thailand menjadi mangsa. Oleh kerana orang Melayu merupakan kaum minoriti dan memandangkan kepada masalah politik dan ekonomi semasa, bolehlah disimpulkan bahawa agama Islam berada pada kedudukan yang kurang memuaskan. Ini berbeza sekali dengan sejarah agama Islam di kawasan tersebut, terutamanya dengan kehebatan guru-guru agama Islam pada awal kurun kesembilan belas. Walau bagaimanapun, kedudukannya pada masa ini tidak dapat dipastikan. Undangundang keluarga Islam juga tidak jelas dan ia terus wujud sebagai suatu pengecualian daripada Kanun Sivil Thailand.

Selain daripada itu, penulisan dalam bidang yang sama telah dihasilkan dalam satu artikel iaitu The Administration of Muslim Law in South East Asia yang ditulis oleh Ahmad Ibrahim (1971: 124-177). Artikel ini memberi tumpuan utama kepada pentadbiran undang-undang Islam di Indonesia, Malaysia dan Singapura. Artikel tersebut turut memuatkan peruntukan pentadbiran undang-undang Islam di negara-negara seperti Thailand dan Filipina sebagai perbandingan dalam memperkemaskan tulisan tersebut. Penulisan mengenai

' Beliau adalah wakil rakyat Changwad Nakornsri Tammarat. Pernah dilantik menjadi Menteri Luar negara Thailand pada tahun 1999-2000. 
pentadbiran undang-undang Islam di Thailand boleh dikatakan lebih ringkas dan pendek.

Analisis mengenai kedudukan undang-undang Islam di lima wilayah selatan Thailand dihasilkan oleh Sulaiman Dorloh (2006: 1-21) dalam artikel beliau yang bertajuk The Position of Islamic Law in the Four Southern Border Province of Thailand. Perbincangan artikel ini lebih memfokuskan kepada kedudukan undang-undang Islam di Patani bermula sejak zaman kegemilangan sehingga ia mengalami kejatuhan. Mengikut sejarah,setelah Pattani dikuasai sepenuhnya oleh kerajaan Siam pada tahun 1789, masyarakat Islam telah mengatur dan menyusun urusan keagamaan mereka dengan bersusah payah bagi mengekalkan identiti keislaman. Imam, khatib dan bilal dalam sesebuah qariyah turut memainkan peranan dalam melaksanakan undang-undang Islam dengan menyediakan ruang terbuka sama ada di serambi masjid mahupun di rumah.

Dalam koleksi suntingan yang sama, satu tajuk artikel yang berlainan tetapi isi kandungan hampir sinonim dengan kedudukan undang-undang Islam di tiga wilayah selatan Thailand dihasilkan oleh Muhammad Zakee Cheha (2007: 121-151) bertajuk The Institution of the Dato'Yuttitam (Qạdī) in Thailand. Perbincangan artikel ini lebih memfokuskan kepada $Q \bar{a} d \bar{l} \bar{d}$ di Tiga Wilayah Selatan Thailand mengikut Hukum Syarak dan Akta Pemakaian Undang-Undang Islam dengan menentukan skop pembenaran dalam

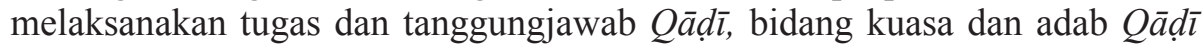
secara perbandingan.

Antara kesimpulan penting yang dibuat oleh beliau dengan mencadangkan bahawa perlu bagi mereka yang akan menjawat jawatan Dato'Yuttitam berkelulusan di bahagian Syariah. Ini kerana bahagian tersebut adalah bahagian yang paling sesuai untuk jawatan tersebut. Begitu juga gaji bulanan. Dicadangkan agar gaji bulanan menyamai kadar dan tahap yang dihasilkan oleh Qā dī Mahkamah Sivil.

Analisis tentang sejarah undang-undang perceraian, prosedur, sebab-sebab, fail perceraian, implikasi yang terdapat kepada pasangan yang bercerai, dan kesan terhadap anak justeru disertai dengan undang-undang Islam dihasilkan oleh Fishaphan Settabut (1982: 5-10) bertajuk Karn Yā (Perceraian). Beliau lebih menekankan kepada latar belakang undang-undang yang berkaitan dengan undang-undang sivil Thai dan juga tatacara hidup rakyat yang lebih menjurus kepada perceraian. Dengan demikian, akan timbul banyak permasalahan dalam masyarakat sama ada wanita dan anak akibat daripada perceraian. 
Sebuah tesis Doktor Falsafah yang dihasilkan oleh Nima Jehtea (2005: 2-10) yang bertajuk Kefahaman Masyarakat Terhadap Pelaksanaan Syariah Islam: Satu Kajian di Pattani. Beliau menyentuh tentang konsep dan teori pemahaman serta menganalisis tentang kefahaman masyarakat wilayah Pattani terhadap pelaksanaan Syariah dalam beberapa aspek dengan secara umum. Aspek-aspek yang dikenal pasti itu ialah aspek ibadat, ekonomi, politik, sosial dan perundangan. Bagaimanapun, beliau tidak menyentuh tentang pelaksanaan undang-undang Islam yang sedia ada di Mahkamah Sivil di wilayah-wilayah masing-masing.

Apa yang dapat diperhatikan dalam penulisan tersebut ialah kesedaran masyarakat Islam berada pada tahap tinggi supaya pelaksanaan Syariah Islam dijalankan dengan lebih menyeluruh, sama ada berkaitan dengan fardu 'ayn atau farḍu kifāyah dan seterusnya hal-hal yang berkaitan dengan undangundang dan negara.

Pada tahun 2004 terdapat dua buah tesis sarjana, pertama ditulis oleh Abdul Rahman Che'arong (2004: 1-7) bertajuk Setti khong farea naikarn yarang lea setti karn dairab tarm kodmai Islam (Hak Isteri dalam Bercerai dan Jaminannya selepas Bercerai mengikut Undang-Undang Islam). Beliau menjelaskan tentang hak yang mesti dipikul oleh suami isteri semasa perkahwinan diteruskan, perceraian dan faktor-faktor yang membawa kepada berlaku perceraian. Perbicaraannya tidak merangkumi pelaksanaan undang-undang keluarga Islam yang berwibawa terhadap tuntutan isteri yang diceraikan apabila didapati haknya tidak dilaksanakan dengan baik.

Manakala yang kedua, Armad Alfariti (2004: 10-15) menghasilkan tesis bertajuk Setti lea Nati Khong Faria Tam Kodmai Islam (Hak dan Tugas Isteri Terhadap Suami dalam Undang-Undang Islam). Secara umumnya beliau banyak menumpukan kepada tugas-tugas isteri terhadap suami semasa dalam ikatan perkahwinan dan kepada keluarga suami mengikut undang-undang Islam. Beliau tidak membincangkan bagaimana isteri boleh menuntut hakhaknya setelah berlaku perceraian, kemudian isu-isu yang ditonjolkan adalah berbentuk lama yang tertulis dalam kitab fiqh.

Empat tahun berikutnya, sebuah tesis untuk memenuhi keperluan ijazah Doktor Falsafah telah dihasilkan oleh Sulaiman Dorloh (2008: 15-20) yang bertajuk The Code of Muslim Family Law and Law of Inheritance 1941: A Critical Study on Divorce and Related Provisions As Applied in the Four Southern Province of Thailand. Secara umumnya beliau membincangkan perkara-perkara yang berkaitan dengan perceraian atau talak dalam pelbagai bentuk yang dibincangkan oleh hukum syarak seperti talak sunnī dan talak bid ' $\imath$. begitu juga dengan bentuk talak yang dilakukan dalam masyarakat di selatan 
Thailand seperti talak melalui cara ta 'liq, fasakh dan khulu ' mengikut Hukum Syarak dan undang-undang Islam yang dilaksanakan di Mahkamah Sivil (kadi) seterusnya beliau membandingkan dengan al-Ahwāl al-Syakhșiyyah yang terdapat di dunia Islam. Namun demikian, beliau tidak menyentuh persoalan hak wanita yang diperolehi setelah berlakunya perceraian.

Dalam tahun yang sama juga, sebuah tesis Doktor Falsafah yang dihasilkan oleh Mesraini (2008: 29) yang bertajuk Hak-hak Perempuan Pascacerai di Asia Teggara: Studi Perundangan Undangan Perkahwinan Indonesia dan Malaysia. Beliau membincangkan tentang sejarah perundangan perkahwinan di Indonesia dan Malaysia, kedudukan perundangan perkahwinan mengikut sistem nasional Indonesia dan Malaysia, seterusnya transformasi fiqhfiqh Islam menjadi perundangan di Indonesia. Selain itu, beliau juga turut membincangkan tentang perceraian, hak-hak selepas perceraian mengikut Undang-Undang Indonesia, justeru diperkemaskan dengan undang-undang keluarga Islam Malaysia. Perbandingan ini dilakukan bagi melihat sejauh mana perbezaan berlaku di antara dua negara di rantau ini dalam menetapkan sumber fiqh sebagai perundangan.

Manakala dalam segmen kajian pula, sebuah kajian yang dianalisis oleh Wantana Klingam bertajuk Karn Yärang Khong Prachakhong Thai (Perceraian Rakyat Thai) di antara tahun B.E.2512-2521 (1969-1978) dijalankan pada tahun B.E.2525 (1982). Hasil kajian tersebut mendapati bahawa perceraian kerapkali berlaku pada lima tahun yang pertama, suami berumur 33-34 tahun manakala isteri berumur 29-30 tahun. Mereka yang muda adalah lebih stabil dari mereka yang berumur tua dan status suami lebih tua dari isteri. Apabila berlaku perceraian, maka tanggungan anak adalah terjatuh kepada isteri.

Pada tahun B.E.2531 (1998), Bunpera'khong Panurat telah melengkapkan tesis sarjana beliau yang bertajuk Pacchai timifhong kratub ta khuam mankhong nai chiwit somros (Elemen yang Berkesan dalam Keteguhan Perkahwinan). Kajian tersebut dijalankan ke atas suami yang bertaraf pegawai kerajaan dan pegawai syarikat swasta. Dalam kajian tersebut, didapati bahawa tempoh umur pasangan yang berkahwin dalam kalangan pegawai berkelulusan sarjana muda dan lulusan tingkatan enam adalah di antara usia 22-28 tahun. Seterusnya, bagi pasangan yang berkahwin sekitar usia 29-36 tahun, hasil pendapatan mereka pula adalah sekitar 3,001-5,000 Baht sebulan, dan golongan yang kedua berada sekitar 5,001-7,000 Baht sebulan. Konflik dalam perkahwinan mempunyai hubungan rapat dengan ketidakstabilan dalam rumahtangga.

Seterusnya kajian bertajuk Setri lea Yärang (Wanita dan Perceraian) dijalankan oleh Supon dan Fanum Limarie (1992: 5). Beliau menggambarkan gambaran umum terhadap peristiwa yang berlaku di mana penganutnya ramai 
beragama Buddha seperti Wilayah Mahasarakham, Kalasin, dan Conkhen. Beliau menyentuh tentang faktor-faktor yang membawa kepada berlakunya perceraian dari pelbagai aspek, sama ada dari aspek kedudukan masyarakat yang mencapai (75\%), kedudukan ekonomi yang mencapai (63\%) dan agama $(62 \%)$. Beliau juga menyentuh tentang kesan-kesan yang hasil akibat perceraian terhadap anak dan seterusnya kepada pasangan itu sendiri. Ringkasnya, perbicaraan ini tidak menyentuh soal-soal perceraian, hak-hak wanita Islam di selatan Thailand yang berlainan sejarah, bangsa dan juga agama.

\section{KESIMPULAN}

Berdasarkan kepada ulasan kajian tersebut, ternyata ada yang dilakukan di luar negara dan ada juga yang dilakukan dalam negara. Walau bagaimanapun, kajian dalam negara sedikit sahaja yang betul-betul dilakukan dalam masyarakat Islam di tiga wilayah selatan Thailand. Kebanyakan kajian adalah berlaku dalam masyarakat Thailand yang lebih ditumpukan kepada aspek perceraian dan punca perceraian. Kebanyakannya berlaku hasil dari tekanan, pendapatan rendah, tidak mempunyai anak, isterinya bekerja di luar rumah dan berlainan latar belakang pendidikan.

Adapun dalam kalangan masyarakat Melayu di tiga wilayah selatan Thai yang majoritinya Muslim, sudah tentu banyak perbezaan dengan masyarakat yang bukan Islam khususnya dari aspek sosio budaya hidup dan penghayatan agama. Islam telah memberikan hak kepada wanita dengan memperuntukkan beberapa hak, sama ada dalam tempoh perkahwinan atau selepas perceraian. Walau bagaimanapun, kajian tentang tuntutan hak-hak wanita selepas perceraian bagi wanita Islam amatlah sedikit jika dibandingkan dengan kajiankajian yang dilakukan dalam isu perceraian.

\section{RUJUKAN}

'Abd. Rahman Che'arong (2004). "Seeti Khong Fariya Naikarn Yā Lea Setti Ti Feng Dairab Tarm Kodmai Islam” (Hak Isteri dalam Bercerai dan Jaminannya Mengikut Undang-Undang Islam) (Disertasi Jabatan Kemanusiaan, Universiti Songkla Nakarin Pattani).

Abdul Kadir Muhammad (1994). "Fasakh Kerana Ketidakmampuan Memberi Nafkah dan Kecacatan Suami”, Monograf Syariah, vol. 2.

Abdul Kadir Muhammad (1996). "Nafkah: Hak Anak dan Kewajipan Bapa", Monogaraf Syariah, vol. 4. 
Ahmad al-Fariti (2004). "Setti lea nati khong faria tarm kodmai Islam" (Hak dan Tugas Isteri Mengikut Undang-Undang Islam), (Disertasi Jabatan Kemanusiaan Universiti Songkhla Nakarin).

Ahmad Ibrahim (1965). The Status of Muslim Women in Family Law in Malaysia, Singapore and Brunei. Singapore: Malayan Law Journal.

Ahmad Ibrahim (1971). "The Administration of Muslim Law in South-East Asia", Malaysian Law Review, vol. 13.

Ahmad Ibrahim (1999). "Undang-Undang Keluarga Islam di Malaysia", Malayan Law Journal.

Ahmad Ibrahim (1978). "Fasakh for Failure to Maintain", Journal of Malaysia and Comparative Law, 229-346.

Fishaphan Settabut (1982). “Karn Yā” (Perceraian) (Disertasi Fakulti UndangUndang Universiti Chulalongkorn).

J.N.D. Anderson (1959). Islamic Law in the Modern World. New York: University Press.

M.B Hooker (1984). Islamic Law in South-East Asia. Singapore: Oxford University Press.

Mesraini (2008). "Hak-hak Perempuan Pascacerai di Asia Tenggara: Studi Perundang-undangan Perkahwinan Indonesia dan Malaysia", (Tesis Kedoktoran, Universitas Islam Negeri (UIN) Syarif Hidayatulla,h Jakarta).

Mohamed Azam Mohamed Adil (1996). "Undang-Undang Pernafkahan Wanita Islam Selepas Perceraian”, Kanun Jurnal Undang-Undang Malaysia, vol. 7 (2).

Muḥammad 'Uqlah (1983). Niẓām al-Usrah fì al-Islām. 'Ammān: Maktabah al-Risālah al-Hadīthah.

Muhammad Abu Zahrah (1957). al-Ahwāl al-Syakhsiyyah. Qāhirah: Dār alFikr al-'Arabī.

Muḥammad Zakariyā al-Bardisī (1970). al-Ahwāl al-Syakhṣiyyah. Qāhirah: Muassasah Sijl al-'Arab.

Muhammad Zakee Cheha (2007). “The Institution of the Dato’Yuttitam (Qāḍ̄i) in Thailand", Jurnal Syariah, vol. 15 (2).

Mușțafā 'Abd al-Ghanī Syībah (2000). Ahkām al-Usrah fì al-Syarī'ah alIslāmiyyah. Sibha: Jāmi'ah Sibha.

Nik Noriani Nik Badlishah (1992). Undang-Undang Keluarga Islam, Nafkah dan Hak-Hak Kewangan Lain. Kuala Lumpur: Dewan Bahasa dan Pustaka. 
Nima Jehtea (2005). "Kefahaman Masyarakat terhadap Pelaksanaan Syariah: Satu Kajian di Pattani”, (Tesis Kedoktoran, Jabatan Fiqh dan Usul, Akademi Pengajian Islam, Universiti Malaya, Kuala Lumpur).

Noel Coulson \& Doreen Hinchcliffe (1978). "Women and Law Reform in Contemporary Islam", dalam Women in the Muslim World, ed. Lois Beck \& Nikki Keddie. London: Harvard University Press.

Noor Awang Hamat (1998). "Status Harta Suami atau Isteri di Sepanjang Perkahwinan", Jurnal Fikrah, vol. 1.

Raihanah Abdullah (2005). "Undang-Undang Keluarga Islam di Malaysia: Satu Sorotan", dalam Mahkamah Syariah di Malaysia: Pencapaian dan Cabaran, ed. Ahmad Hidayat Buang. Kuala Lumpur: Jabatan Syariah dan Undang-Undang, Universiti Malaya.

Raihanah Abdullah (2001). "Nafkah: Peruntukan Undang-Undang dan Pelaksanaannya", Jurnal Undang-Undang IKIM, vol. 5 (1).

Raihanah Azahari (2001). "Mut'ah al-Talak: Wanita Manakah yang Berhak Menerimanya", dalam Wanita dan Perundangan Islam, ed. Raihanah Abdullah. Kuala Lumpur: Ilm Publishers.

Sharifah Zaharah Syed Mohammad (2001). "Hadanah: Pelaksanaan Menurut Akta Undang-Undang Keluarga Islam Wilayah Persekutuan 1984”, dalam Wanita dan Perundangan Islam, ed. Raihanah Abdullah. Kuala Lumpur: Ilm Publishers, 160-200.

Sulaiman Dorloh (2006). "The Position of Islamic Law in the Four Southern Border Province of Thailand", Jurnal Syariah, vol. 14 (2).

Surin Pitsuan (t.t.). Islam di Muang Thai: Nasionalismen Masyarakat Melayu Pattani (terj) Hasan Basari, cit. 1. Jakarta: LP3ES. Judul asal buku ini ialah Islam and Malay Nationalism: A case Study of The Muslim of Southen Thailand

Suwaid Tapah (2003). "Konsep dan Amalan Pembahagian Harta Sepencarian di Malaysia", dalam Harta Sepencarian, Prosiding Ex-Parte dan Perintah Injuksi, ed. Tajul Arus Ahmad Bustani et al. Selangor: Kulliyyah Undang-Undang UIAM.

Suwaid Tapah (1998). "Peruntukan Nafkah Anak di dalam Undang-Undang Keluarga Islam di Malaysia", Jurnal Fikrah, vol. 1.

Zakī al-Dīn Sya‘bān (1964). al-Zawāj wa al-Ṭalāq fì al-Islām. Qāhirah: al-Dār al-Qawmiyyah li al-Ṭabā'ah wa al-Nashr.

Zaleha Kamaruddin (1998). Introduction to Divorce Law in Malaysia. Selangor: IIUM Cooperative Ltd. 
Journal of Shariah Law Research (JSLR) 